\title{
Social Media and Consumer Behavior - How Does it Works in Albania Reality?
}

\author{
Prof. Assoc. Dr Elenica Pjero (Beqiraj) ${ }^{1}$ \\ Prof. Dr Donika Kërcini²
}

\begin{abstract}
Department of Business Administration, Faculty of Economy, University “Ismail Qemali”, Vlore, Albania; E mail: e.pjero@yahoo.com Head of Agribusiness Management Department, Faculty of Economics and Agribusiness Agricultural University of Tirana, Albania; E mail: donika@kercini.me
\end{abstract}

Doi:10.5901/ajis.2015.v4n3s1p141

\section{Abstract}

Nowadays, Social Media represent a new sophisticated and uncontrollable element influencing consumer behavior. They have also dramatically changed the way businesses and consumers communicate with each other. This paper is focused on Social Media and their ability to influence consumer behavior world-wide and specifically in Albania reality. The adaption and growing popularity of Social Media by so many users world-wide is first discussed. It is examined the reasons for the use of Social Media and user attitudes towards them. Then the authors proceed with a multidimensional examination of the impact Social Media have on users' consumer behavior and purchase intentions. The survey data are from all users of Social Media and this led to significant results about consumer behavior.

Keywords: consumer behavior, social media, attitudes, purchases intentions, communication.

\section{Introduction}

Nowadays we live in an environment that is constantly changing, where everything is characterized by the economic crisis and a crisis of values, and where human need for communication and exchange of views has become even more important. It is in such an environment, social media found the field to be developed and to take their place in the daily lives of people. As any acquisition of a new trend, social media also contributed to each of our everyday space.

It is a fact now, that Social Media have introduced a new complex and uncontrollable element affecting the behavior of consumers and which have dramatically changed the way consumers and businesses communicate with each other (Hennig-Thurau \& al., 2004). Today, consumers are using social media as an effective tool in their purchasing experiences. Through them they gather information, communicate and share ideas with other consumers for products and services, and are in direct contact with companies and brands they prefer. All these elements constitute a new generation of consumer, called Social Consumer generation.

Social media have a real impact on consumer behavior. Their ability stems mainly from factors such as eWOM, advertising, official business profiles, which someone meet in the world of Social Media. Purchasing decisions is always affected by social influence. The social impact is simply attained on line by Social Media.

This study through a combination of literature and empirical research aims to examine and interpret the ability of social media to influence consumer behavior and intent to purchase goods or services, taking into account a number of factors such as advertising, eWOM, the presence of businesses with official profiles in Social Media.

\section{Review of Literature}

According to Mayfield (2008), Social Media present some basic features such as :

- Participation: media encourage the contribution and comments from concerned parties. This usually weakens the borders between media and public.

- Openness: almost all social media services are open for participation and feedback, but there are not always barriers to enter and use the contents.

- Conversation: unlike traditional media who is only related to broadcasting toward the audience, Social Media represent a two crossings chat.

- Community: Social Media allow to directly establishing communities that share common interests, such as 
their affection about pictures or TV shows.

- Connectedness: Most types of social media connect to other sites, resources and people to develop its stability.

$U$ \& G Theory, can better explain why we use the media in general and social media in particular. According to McQuail (1994) there are four incentives that push us to use: 1) information, 2) entertainment, 3) social interaction and 4) personal identity.

Brandtzæg \& Heim (2009) in their research, in the light of the theory U \& G, considered reasons for using social networking sites, which constitute the most known part of social media. The research was conducted in Norway, with over 4000 participants from whom he selected only about 1,200 to ensure the solvency of the investigation. It seemed that the most important reason to use social networks was to meet new people and the second most important was to communicate with friends. Followed in descending order, there are other reasons such as: the reason for socializing, information gathering, discussions and exchanges of views with other people. The findings matched the pattern of $U$ \& $G$ theory and show that the main purpose of the use of social networking is social interaction, that is, communication between people.

A similar study was conducted by Dogruer \& al (2011), and was focused entirely on incentives that push the new generation in the use of Facebook. The search was conducted in the Eastern Mediterranean University, including a total of 302 participants. Participants were asked to choose between a multitude of words based on usage, such as: to play games, to flirt, to communicate with others, to promote themselves and take positive comments, to spend more beautiful your free time, to see pictures. Results of the study showed that the most important reason for students to use the specific social network of students was to "meet" and communicate with people they already know, and to restore their relationship with people who had forgotten.

Seeking Li (2007) conducted in the USA, showed that the main reason for the use of social media by the Americans, was the desire of users to connect and communicate with their friends.

Finally, according to the World Report on Social Media in 2012 (Nielsen), predominant reason for using social media continued to be the user's desire to keep contacts with people who already know. Other minor reasons are: to collect information about global developments etc.

Modern Social Media now is implemented in the fields of science, education, labor, operational areas, and even medical applications.

Albania counts a population of 3,020,209 inhabitants. The vast majority of the inhabitants are Albanians, with ethnic minorities which represent only about $2 \%$ of the population. Minority population is mainly composed of Greeks and Macedonians. In 2014, users of social networks in Albania reached a total of $1,815,145$ or $60.1 \%$, according to the ITU (International Telecommunication Unit).

According to a study (2003), conducted in 2903 participants, consumers tend to look for information sources and more specifically eWOM opinions of other customers online, for the following reasons:

- To decrease the risk and time of research.

- To evaluate products, because of the social orientation through information

- To feel a part of the community.

- To learn how to consume a product

Finally, according Frederix (2008), the most important reason that leads consumers to this process is due to the usefulness of the source of information, which leads to better decisions and faster purchase.

\section{Research Methodology}

In this study, the aim is to know the amount of influence that electronic media have in consumer behavior and desire to consume of the Albanian users. The sample consists of 116 people, including 55 females and 61 males. Women make up $47 \%$ and men $52 \%$ of the selected sample. $3 \%$ of them are aged $12-17$ years, $77 \%$ aged $18-24,18 \%$ aged $25-30,1 \%$ and 1\% 31-40 age group over 40 years old. Regarding the level of education, there are not students of primary school, $16 \%$ of them are high school students, $17 \%$ have completed secondary school and $66 \%$ are master graduated, and $1 \%$ are doctoral graduates.

$52 \%$ of respondents were in labor relations during the course of the study, while $48 \%$ were not.

The methods used for this study are: a) the method of primary data collection, which is known as quantitative method and is based on a survey with a standardized questionnaire and through

b) the review of international literature for secondary data. 
The questionnaire was the main tool for collecting primary data in this research. The high intensity of the questionnaire use as a primary method of gathering information on similar studies in the literature, contributed decisively to use the same method in this research. Further advantages offered by the use of such an instrument to collect data, also assisted in the decision.

To ensure cooperation with the respondents, the questionnaire should be short. The respondent is asked to be honest, accurate, and only, to all the questions and return the questionnaire back to the researcher. These given question and answers will then be analyzed and based in them conclusions will be drawn. The answers received from the questionnaire can be categorized as: knowledge and information (i.e. what the interviewee knows), value and preferences (i.e. what the interviewer like and do not like) and the attitudes and beliefs (i.e. what the interviewee think). All these elements are important for the success of a questionnaire.

\section{Results}

Regarding the use of electronic network, there were no people who stay online less than 1 hour per day. $28 \%$ claims it is 1-2 hours per day, 35\% stayed 2 - 4 hours and $37 \%$ more than 4 hours a day. Connection to the Internet is carried out mainly from home and facilities with $\mathrm{Wi}-\mathrm{Fi}$, and there is also a good part of them (48\%) who say they are on the web via their mobile phone. Almost all (99\%) of them use the electronic media, while $83 \%$ of them claim to have even their profile on a website.

By studying the amount of some specific electronic media use in two dimensions (amount of use and the order of preference), the conclusion is that the most famous social networks are Facebook, YouTube, Wikipedia, Google Plus, while Linked In, every day increases the number of users in Albania having $31 \%$ of the responders to use it, but not on a daily basis. On the other hand, $90 \%$ of users state that Facebook is used in a daily base, a trend that agrees with the reality, as we saw in the theoretical study where we found that Facebook represents "monopoly" of the social network.

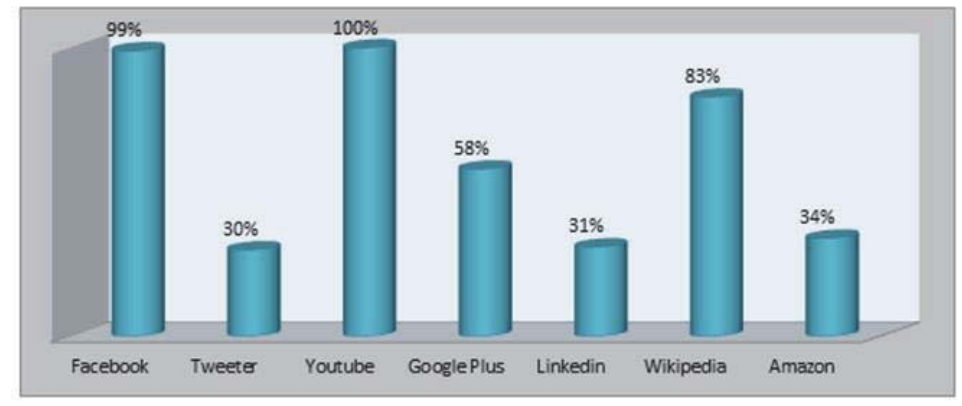

Figure 1. Social networks use

Twitter is used by $30 \%$ of the sample, with daily users to grow in number. YouTube is used from $100 \%$ of the users. Linked In is considered a professional website with users growing slowly. The most active users of social media are aged 18-24, except Linked In, where users which are mainly postgraduate degree or doctoral degree. In particular, active Facebook users are 18- 24 years old, Twitter 17-30 years old and YouTube 25-30 years old.

It became clear that the main reason for using social media to communicate with other people, especially with the old classmates and friends, family or famous people who are abroad.

$60 \%$ of respondents use social networking sites to communicate,

$52 \%$ say that the reason for the use of social media is the contact with old friends

$58 \%$ of respondents claim that social media are useful to communicate with relatives and friends abroad only $26 \%$ agree on the idea that social media is used to create new contacts. 


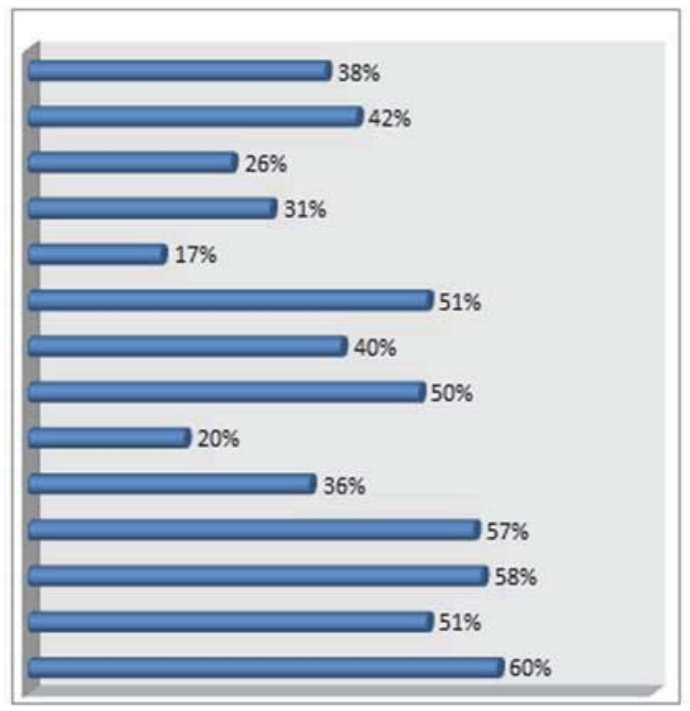

Figure 2. Why is Social media used?

The second main reason to use social media is to inform them about the social and political developments. $56 \%$ use social networking sites to be informed about social developments. $21 \%$ have identified a form of entertainment in social media through games and 50\% said they use social media services in the field of music and movies.

The vast majority of users (85\%) argues that the Internet is a source of research information to make their purchases, $61 \%$ of the sample makes purchases online, $21 \%$ of the sample watch advertisement in social media in a very interesting way, 20\% noticed advertising whenever they are interested in the product advertised and $22 \%$ look at them occasionally, $40 \%$ said that has been updated for at least one product through social media, 33\% say they occasionally shares his purchasing experience and only $13 \%$ always share their experience when they are satisfied with their buying experience. $88 \%$ say they are members of a particular brand in social media and the main reason is the update for bids.

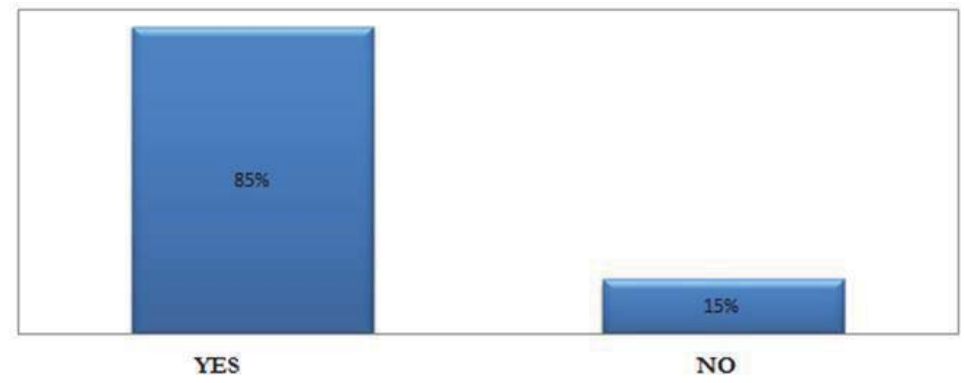

Figure 3. Do you search in internet about a product before purchasing it?

$14 \%$ do not agree with their suggestion that their consumer behavior is influenced by social media, $31 \%$ are neutral on this proposal, while $55 \%$ disapprove. Therefore it is clear that half of our sample admitted the impact of social media in their consumer habits. $43 \%$ of them said that the experience of shopping interacts with other customers, and $42 \%$ neither agree nor disagree with this proposal, $15 \%$ responded negatively. $44 \%$ say they have confidence in the value of great customer reviews of other publications that they make in their profiles or social networks in general while $21 \%$ disagree. $35 \%$ neither are nor disagree. Only $41 \%$ said they are influenced by the number of consents (like) or comments about buying a product. 30\% disagree with this proposal and 29\% neither are nor disagree. 
Users under the age group they belong, use social media for various reasons. More specifically, users aged above 17 use social media to communicate with friends more than other age groups. Because it was not possible to find a study to establish the theoretical foundations of this result, we can assume that the evidence available is that, bigger the market in which interacts a consumer, more social media he uses to decide on purchases.

\section{Conclusions and Recommendations}

Using social media appears to positively affect consumption behavior of users. The social media affects differently both genders in the purpose of buying and in the consumer behavior. Although we can't get reliable conclusions about most influenced gender, our results confirm various surveys, which suggest that the factor "Gender" differentiates the degree of impact on consumer behavior through social media (Frederica RUDEL, 1995; Thompson \& Lougheed, 2012). Information on the Internet about products and services positively affects the intention to buy. Also, registering as a member / friend / fan / follower on the page profiles of companies, products, services, increases even the intention to purchase products (or products of this company) and consumer behavior with respect to these products, thereby increasing the chances of market .

Another interesting finding that emerged from regression is that people who show themselves in Social Media have limited opportunities to be influenced in their intention of purchase by other users.

Some interesting results include:

$>$ The great part (60\%) of the sample uses a certain form of Social Media.

$>$ It is seen a daily use of social media.

$>$ The main reason for the use of Social Media is communication with other people, especially with old teammates, friends and family or famous people who are abroad. The second main reason for the use of social media is to inform the social and political developments.

$>$ The most common activity performed in Social Media is reading content (spectator), and there is very little activity in the creation of content (creative). Also commenting on the content is the preferred activity of the sample.

$>$ A large part of the sample agrees exactly with the idea that positive eWOM within social media, positively influences the intention to purchase a product/service.

$>$ Half of the sample agrees exactly with the idea that consumer behavior is influenced by Social Media.

$>$ Whatever the reason for the use of Social Media, intent to purchase and consumption behavior of some users seem to be affected.

$>$ Social Media users are influenced in their consumer behavior in all its spectrum. Users seek for information on the Internet and Social Media for products, services, brands and say they are influenced by eWOM consumers, advertising and the presence of companies and brands with official profiles and membership pages within them.

$>$ Internet and Social Media updates for products and services increase market opportunities.

$>$ Registration as a member / friend / fan / of a brand / company / product at social media networks affects the intention to purchase and consumption behavior of users.

$>$ Social Media users despite the fact that they use them, they also recognize negative characteristics of Social Media, which impact the positive influence in purchase

$>$ To fulfill social needs and improving self-confidence through the use of social media has a negative relationship with their ability to influence the willingness of consumers to buy products / services. Social "Pleasure" overshadowed consumer behavior.

\section{References}

Mayer A., (2009), "Online social networks in economics", http://sistemas-humano-computacionais.wdfiles.com/local--files/capitulo\%3 Aredes-sociais/amayer.pdf

Boyd \& Ellison (2008), "Social Network Sites: Definition, History, and Scholarship", Journal of Computer-Mediated Communication, Gunawardena Charlotte N, Mary Beth Hermans, Damien Sanchez, Carol Richmond, Maribeth Bohley, and Rebekah Tuttle, (2009), "A theoretical framework for building online communities of practice with social networking tools".

Deiworldwild (2008) http://www.experian.com/assets/simmons-research/brochures/experian-marketing-services-2011-social-media-consumer -report 2.pdf

Charlene Li (2007). "How consumers use social networks". http://www.eranium.at//blog/upload/consumers_socialmedia.pdf 
Gunawardena Charlotte N, Mary Beth Hermans, Damien Sanchez, Carol Richmond, Maribeth Bohley, and Rebekah Tuttle, (2009), "A theoretical framework for building online communities of practice with social networking tools", Educational Media International, http://marybethhermans.synthasite.com/resources/SocialNetwrkingWeb2.0.pdf

Mitchell Clyde (1974), "Social Networks", Clyde Nuffield College, Oxford, England Pescosolido Bernice (2006), "The Sociology of Social Networks", Indiana University.

Kaplan, A. M. \& Haenlein, M., (2010), "Users of the world, unite! The challenges and opportunities of Social Media. Business Horizons", Vol. 53

Kaplan A. M., Haenlein M., (2009 a), "The fairyland of Second Life: About virtual social worlds and how to use them", Business Horizons, Vol. 52 